\title{
Microprocessor-Based Design of a Firing Circuit for Three-Phase Full-Wave Thyristor Dual Converter
}

\author{
PEI-CHONG TANG, SHUI-SHONG LU, AND YUNG-CHUN WU
}

\begin{abstract}
A firing scheme based on a microprocessor to control an antiparallel-connected three-phase thyristor dual converter is presented. Using table-look-up algorithm to speed up the response, it gives a full range control of the firing angle between $0^{\circ}$ and $180^{\circ}$ for both positive and negative current control. The maximum time delay required to correct the firing angle is one-sixth period of the ac power source. The firing angle between $120^{\circ}$ and $180^{\circ}$ is used for the regeneration braking to achieve the required dynamic performance in four quadrants. Built with all digital circuits with no further adjustment, this system is more reliable and has lower cost.
\end{abstract}

\section{INTRODUCTION}

$\mathbf{T}$ HYRISTOR-FED dc motors are being used increasingly in general industrial applications. To give a fast response, the antiparallel-connected three-phase full-wave thyristor dual converter usually provides four-quadrant operation. Several firing schemes employed six identical phase control units to achieve higher performance [1]-[3]. Based on analog techniques these schemes required a number of components and careful adjustments. By using a divide-by-six counter to select the firing sequence, it was able to reduce the number of components [4]. In recent years, the microprocessor technique has been applied to general dc motor control systems for higher performance [5], [6]. The interface circuits between microprocessor controller and original firing circuit tend to increase the overall cost and decrease the advantage of microprocessor.

In this paper, a microprocessor-based firing scheme is presented. Together with software algorithm in microprocessor, the digitized ac power signals are used to find the correct firing output signals. This scheme uses less hardware components and has higher dynamic performance in four-quadrant operation.

\section{SCHEME DESCRIPTION}

Fig. 1 shows the block diagram of the antiparallel-connected three-phase dual thyristor converter with the firing circuit. The complete firing circuit is given in Fig. 2 to be described below.

Manuscript received March 6, 1981.

P.-C. Tang is with the Institute of Electronics Engineering, National Chiao-Tung University, Hsinchu, Taiwan, Republic of China.

S.-S. Lu is with the Department of Mechanical Engineering, National Taiwan University, Taipei, Taiwan, Republic of China.

Y.-C. Wu is with the Department of Control Engineering, National Chiao-Tung University, Hsinchu, Taiwan, Republic of China.

\section{Dual Thyristor Converter}

A given SCR in the antiparallel-connected three-phase thyristor dual converter can be triggered to conduct by firing the gate when the anode voltage becomes positive relative to the cathode voltage. The six SCR's in group $A$ control the positive current and the six SCR's in group $B$ control the negative current. At any instant, the loading current exists only when a pair of SCR's in the same group are conducting, as shown in Table I.

\section{Power Signal Operation}

The ac source is isolated and fetched by three identical single-phase filament transformers. After amplification and saturation, the digitized three-phase power signals, $\phi A, \phi B$, and $\phi C$ are obtained. These digitized signals, $\phi A, \phi B$, and $\phi C$ are sent to the microcomputer. The relationships between line voltage $V_{a b}, V_{b c}, V_{c a}$, and these digitized signals are shown in Fig. 3.

\section{Frequency Doubler}

A monostable multivibrater is used to produce two pulses, one at the rising edge and one at the falling edge of each digitized signal. The basic circuit and waveforms of each frequency doubler are shown in Fig. 4. Combining these sets of pulse signals, a base interrrupt signal, B. I., is obtained. The base interrupt signal, B. I., has a frequency six times that of the ac source, as shown in Fig. 3(g). The interrupt signal occurs at each of phase angles, $0^{\circ}, 60^{\circ}, 120^{\circ}, 180^{\circ}, 240^{\circ}$, and $300^{\circ}$ of the ac source. A new firing cycle is started at the falling edge of the base interrupt signal, B.I..

\section{Firing Angle Control}

An 8-bit single-chip microcomputer, $Z 8$, is used as the main controller of the thyristor dual converter. $Z 8$ is a complete microcomputer including CPU, $2 \mathrm{~K}$ bytes of ROM, 124 bytes of general purpose register, two 8-bit bytes of ROM, 124 bytes of general purpose register, two 8-bit timers with 6-bit prescales, 32 bits of $\mathrm{I} / \mathrm{O}$ including one serial $\mathrm{I} / \mathrm{O}$ and 6 levels of interrupt. The block diagram of $Z 8$ is shown in Fig. 5. The programs in the microcomputer include firing range selection, firing pulse generation, crossover protection and processes used for general servo system.

Firing signals are sent to a chosen pair of SCR gates at the same time for both continuous and discontinuous current modes, as shown in Fig. 6. Each firing signal contains several pulses of 30- $\mu$ s period. Coupling with pulse-transformers, this 


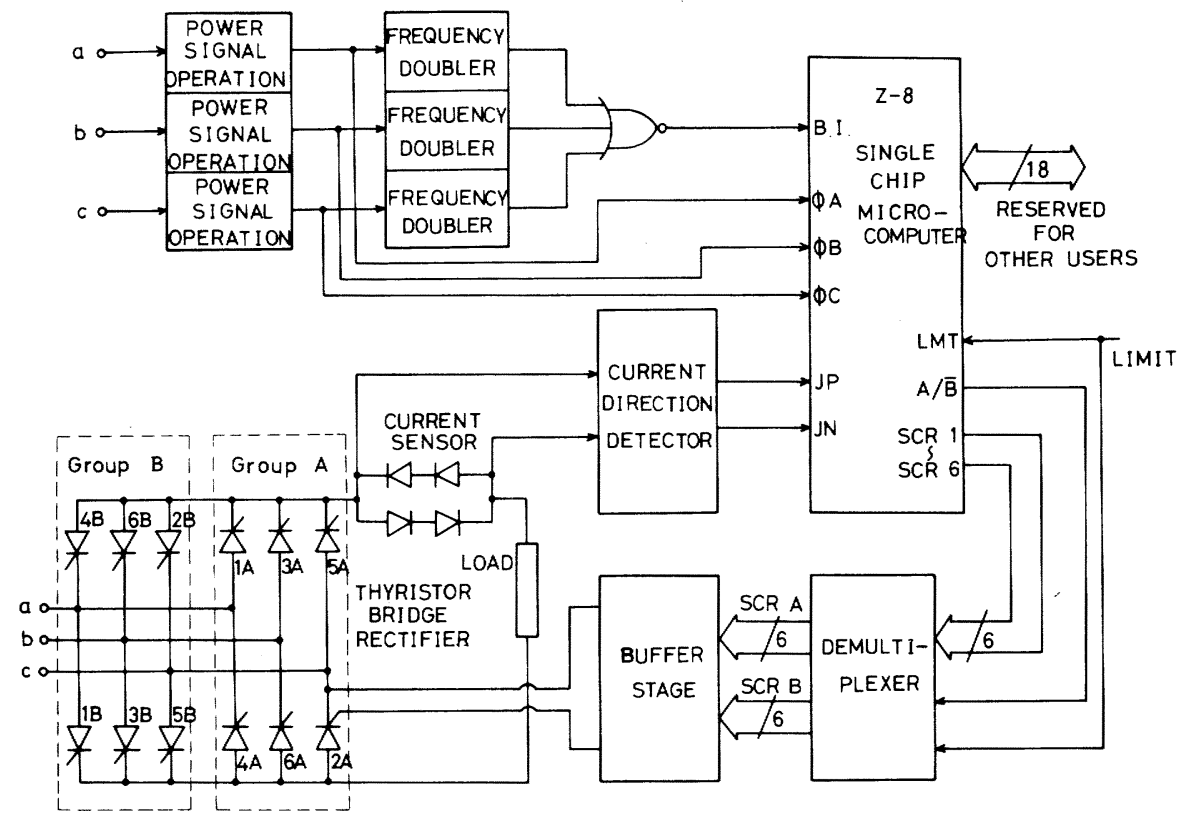

Fig. 1. System block diagram.

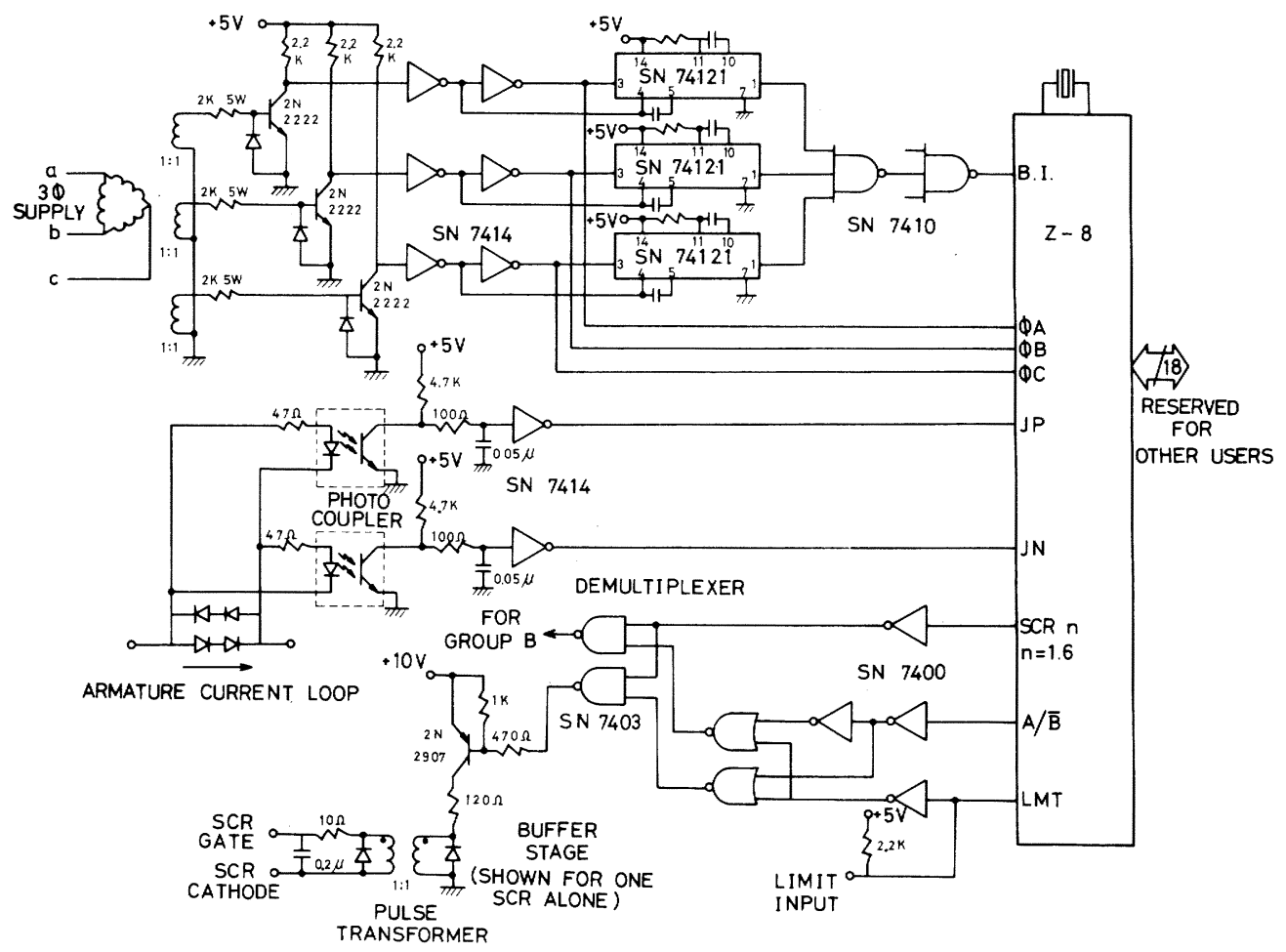

Fig. 2. Firing circuit.

TABLE I

CONDUCTING SEQUENCE OF SCR'S

\begin{tabular}{|c|c|}
\hline Conducting SCRs & Power Source \\
\hline SCR 1, SCR 2 & Vac \\
\hline SCR $2, \operatorname{SCR} 3$ & $V b c$ \\
\hline $\operatorname{SCR} 3 \cdot \operatorname{SCR} 4$ & $v b a$ \\
\hline $\operatorname{SCR} 4, \operatorname{SCR} 5$ & vca \\
\hline SCR 5, SCR 6 & $V_{c b}$ \\
\hline SCR 6. SCR 1 & $V a b$ \\
\hline
\end{tabular}




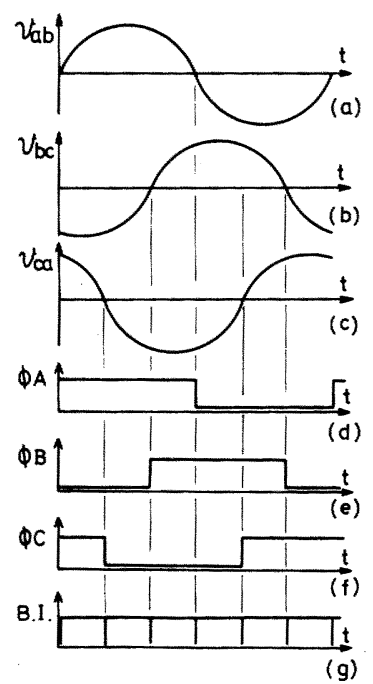

Fig. 3. Digitized power signals and base interrupt.
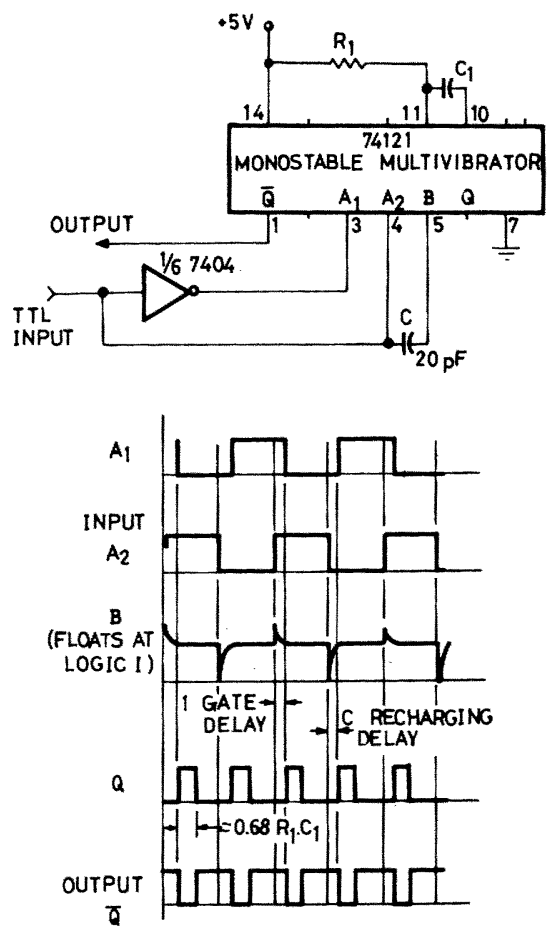

Fig. 4. Circuit and waveforms for the frequency doubler.

type of firing signals will fire the SCR's reliably. By using the algorithm of microcomputer software, the generation of firing signals is implemented with minimum hardware circuits.

The firing angle command is stored in two registers of the microcomputer, which can be changed by other programs. The firing angle command contains 8 -bit absolute data, $D 7-D 0$, and one-bit data, $A / \bar{B}$. The maximum value of $D 7-D 0$ corresponds to a firing angle of about $239^{\circ}, D 7$ and $D 6$ indicate one of the ranges of $0^{\circ}-59^{\circ}, 60^{\circ}-119^{\circ}, 120^{\circ}-179^{\circ}$, and $180^{\circ}$ $239^{\circ}$. $D 5-D 0$ represent the angle from $0^{\circ}$ to $59^{\circ}$ and the unit of timing is $1 / 60 / 6 / 64=43: 4 \mu \mathrm{s} . A / \bar{B}=1$ indicates positive current control and $A / \bar{B}=0$ indicates negative current control. During the one-sixth period of ac source, there are six sources to be controlled. For example, if the digitized power

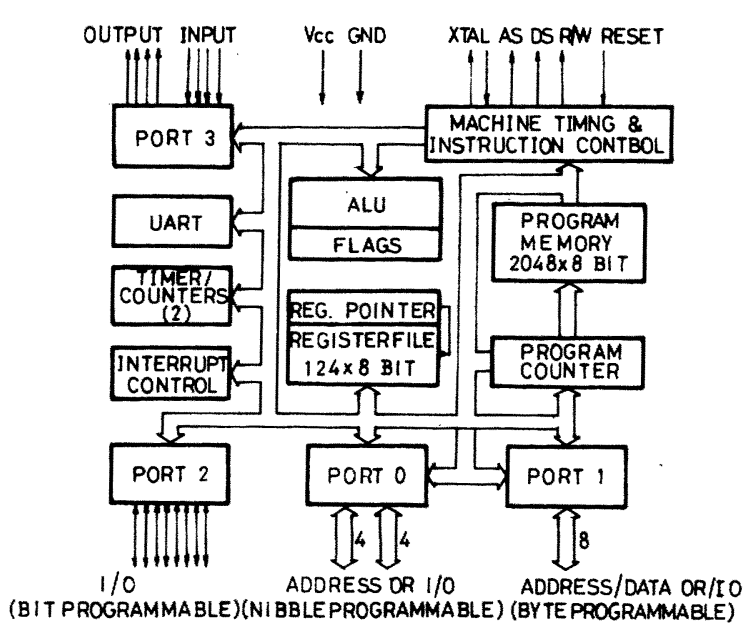

Fig. 5. Z8 microcomputer block diagram.

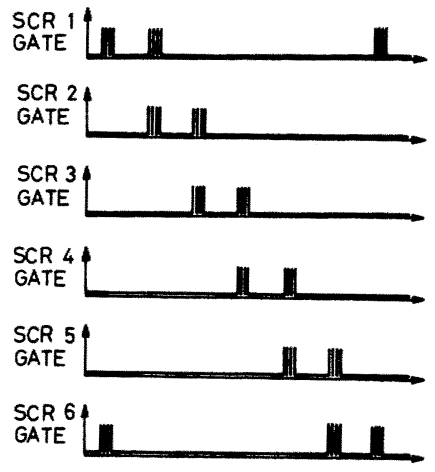

Fig. 6. SCR gate signals.

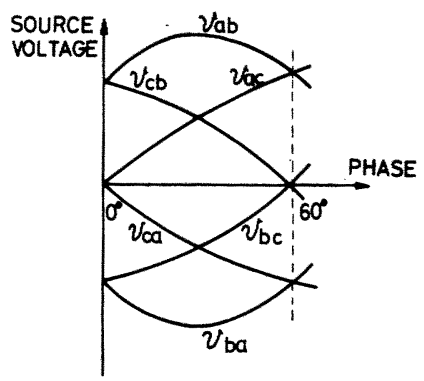

Fig. 7. Power source voltage signals.

signals are $\phi A=1, \phi B=0$, and $\phi C=0$, the wave forms of the power sources are shown in Fig. 7. In this case, the power sources, $V_{a b}, V_{c b}$ and $V_{c a}$, are used to control the positive current and the power sources, $V_{b a}, V_{b c}$, and $V_{a c}$, are used to control the negative current. If the positive current is controlled, $V_{a b}$ will be chosen as the power source in case the firing angle is in the range of $0^{\circ}-59^{\circ}$, and $V_{c b}$ will be chosen if the range is $60^{\circ}-119^{\circ}$, and $V_{c a}$ will be chosen if the range is $120^{\circ}-179^{\circ}$. The firing range of $180^{\circ}-239^{\circ}$ is disabled. By this algorithm, the full range of $0^{\circ}-179^{\circ}$ can be controlled within one-sixth period of ac source. Thus the design of overall system compensation is simplified and the overall response is increased.

The firing range selection is implemented by table-look-up 


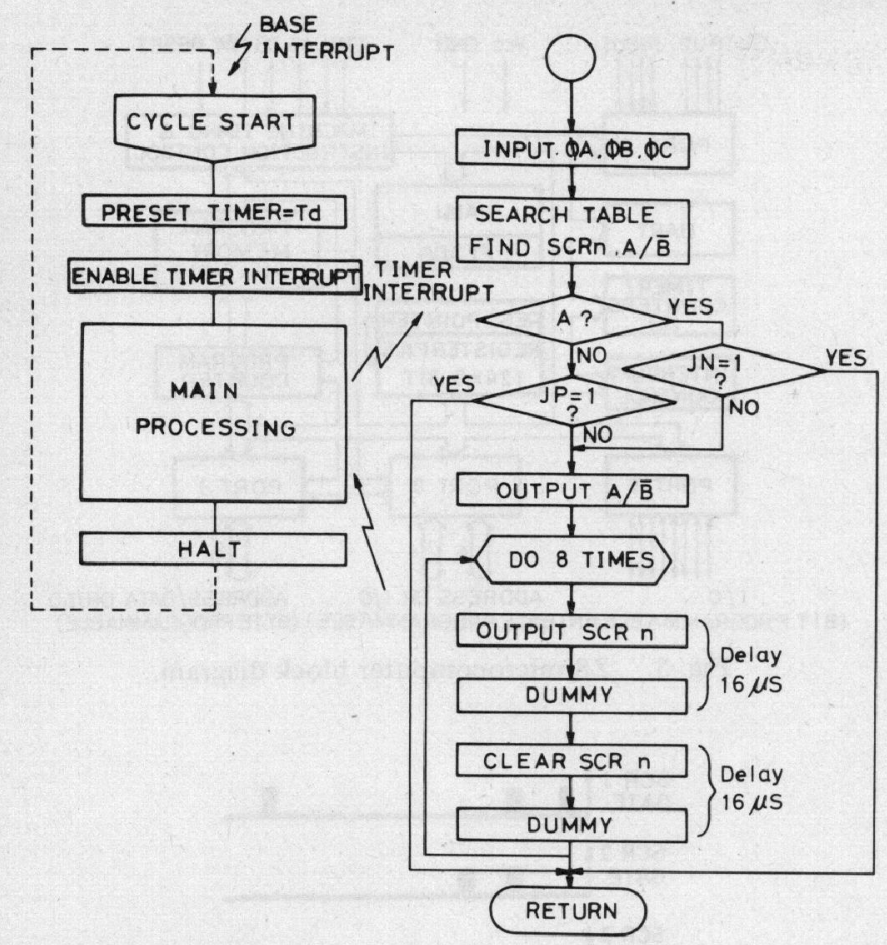

Fig. 8. Flowchart for firing control.

TABLE II

TR UTH TABLE FOR FIRING CONTROL

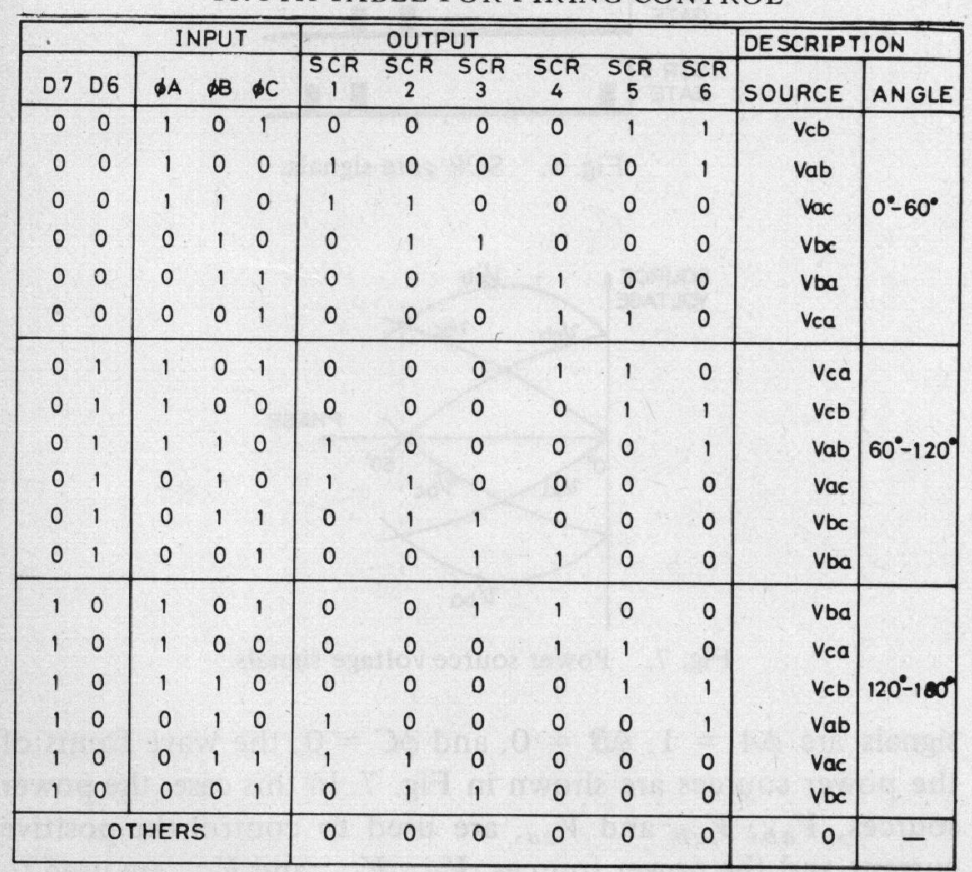

alogirthm as shown in Table II. The flow chart for the firing control program is shown in Fig. 8. A new control cycle is initiated at the occurrence of each base interrupt signal, B.I.. The microcomputer sets the timer with the delay angle indicated by $D 5-D 0$, then continues to process other jobs such as velocity loop compensation, position loop compensation, and so forth. When the timer counts down to zero, a timer interrupt is received and the firing process is started. First, the digitized power signals, $\phi A, \phi B$, and $\phi C$ are read in. Combined with the range indicator, $D 7$ and $D 6$, the firing code is fetched by table-look-up. After checking the protections, the firing

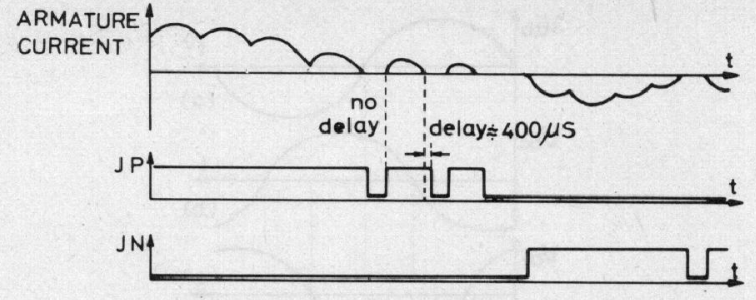

Fig. 9. Current direction signals.

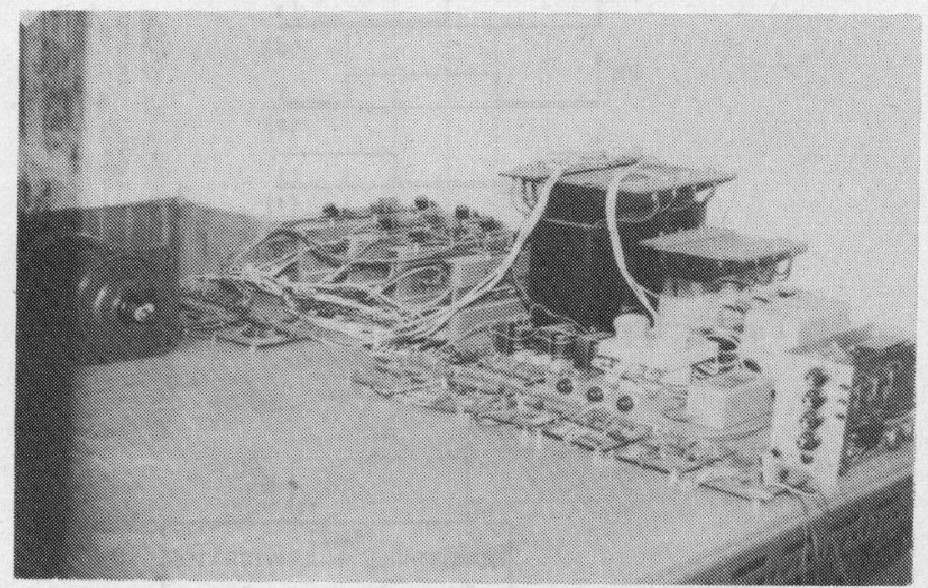

Fig. 10. Photograph of the whole experimental setup.

signals are sent to fire the gates of chosen thyristors. At the end of the firing process, the microcomputer will continue to process the interrupted program.

The computing time of the overall firing process is less than $400 \mu \mathrm{s}$ per cycle, that is 15 percent of one-sixth of the period of the ac source. 14 bits of I/O and less than 256 bytes of ROM are used. Therefore, the microcomputer is able to do other jobs in a general purpose servo system.

\section{Demultiplexer and Buffer}

The firing signals for group $A$ and group $B$ are demutiplexed by hardware circuits to save the $\mathrm{I} / \mathrm{O}$ of microcomputer for other usages. After six one-line to two-line demultiplexers the signals are amplified to drive the pulse transformer, and the gates of the chosen thyristors are then fired.

\section{Current Direction Selection}

The conducting condition of the SCR's in dual thyristor converters can be detected by fetching the condition of load current instead of checking the SCR's. If the positive load current exists, some SCR's are conducting in group $A$. Due to the off-time characteristics of SCR's, if the positive load current does not exist, it does not mean that there are no SCR's conducting in group $A$. This is also true for the case of negative load current. With isolation by photocouplers, the current direction signals, $J P$ and $J N$, are taken from the voltage across the anticonnected four diodes in series with the armature current loops. When the load current decreases to zero, the current direction signals are delayed by about $400 \mu$ s before turning off to ensure that SCR's has turned off, see Fig. 9. This time delay is much longer than the off-time for most types of SCR's. Thus when the current direction signals, $J P$ and $J N$, are zero, one is sure that no SCR's are conducting. If one of the current direction signals is not zero, the SCR's in 


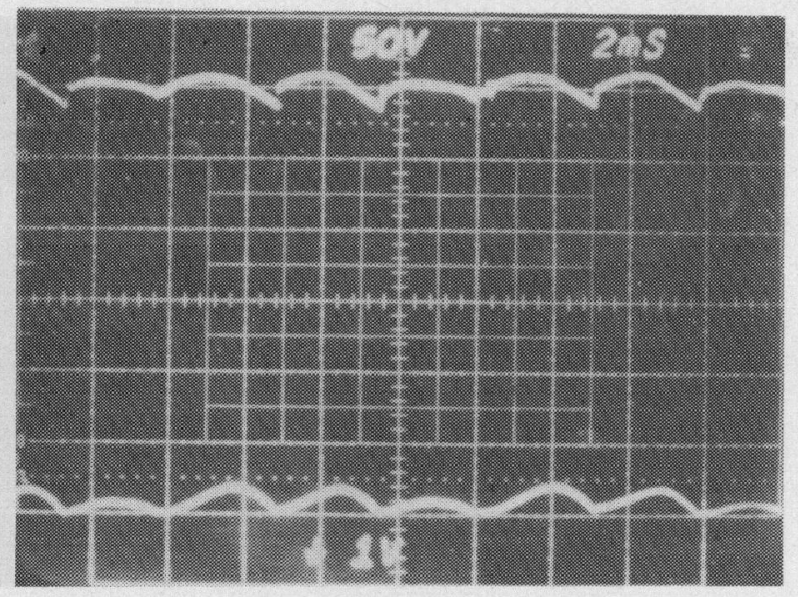

(a)

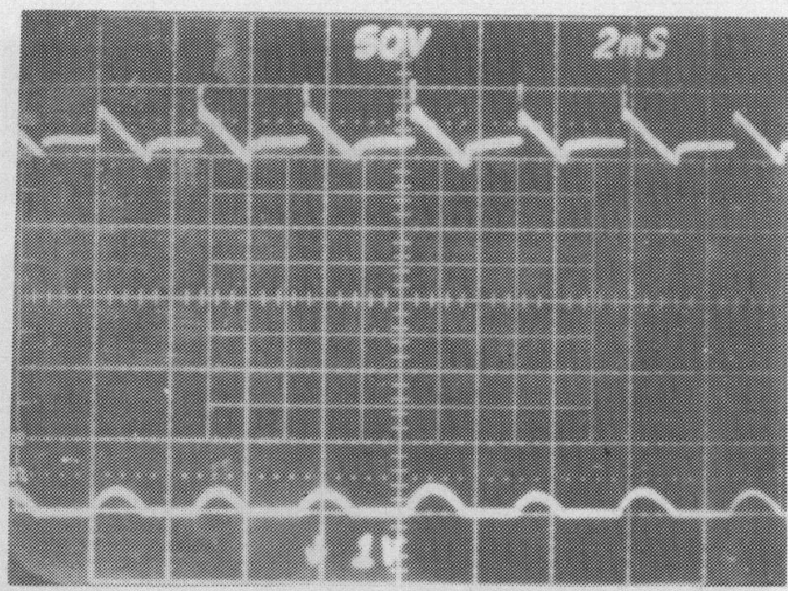

(c)

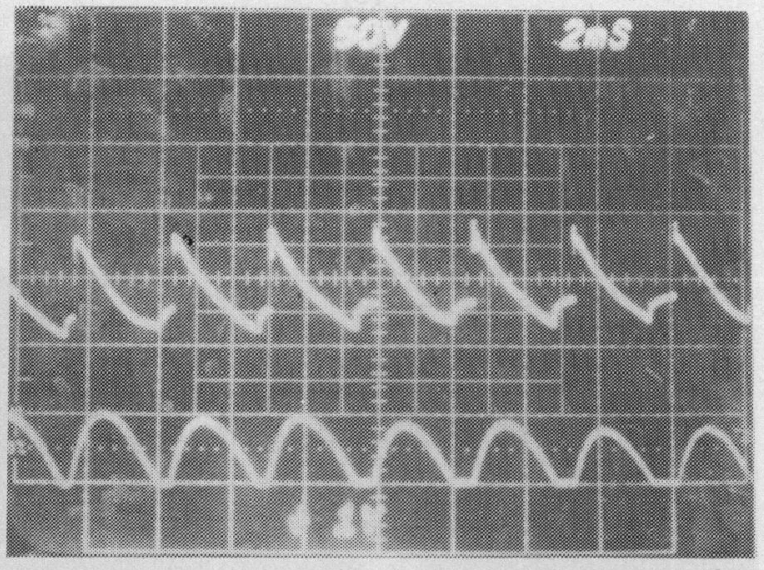

(e)

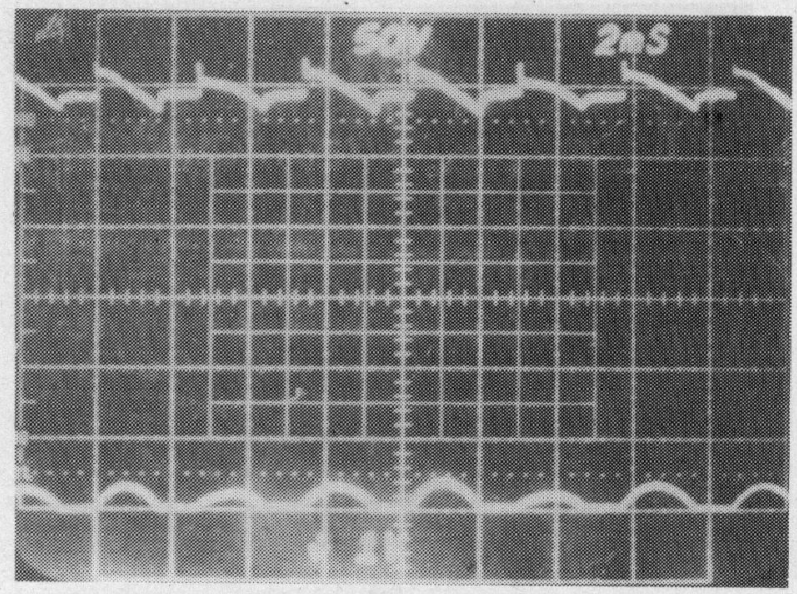

(b)

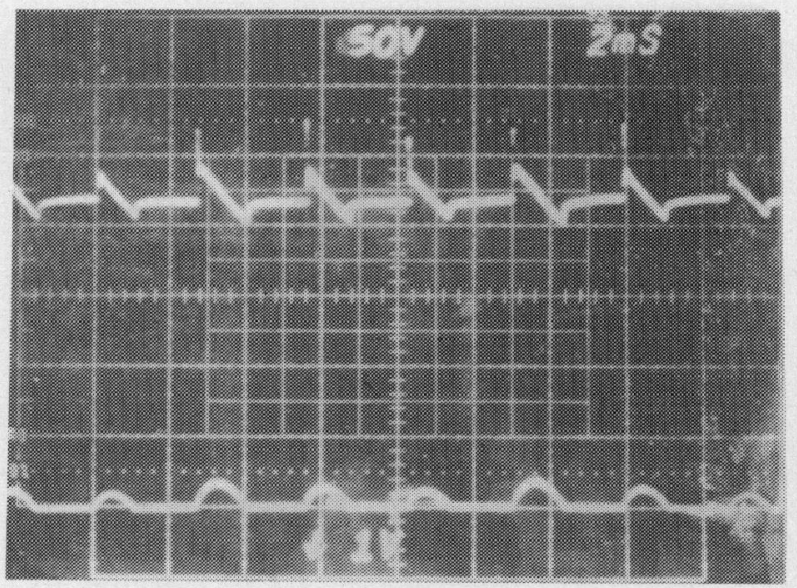

(d)

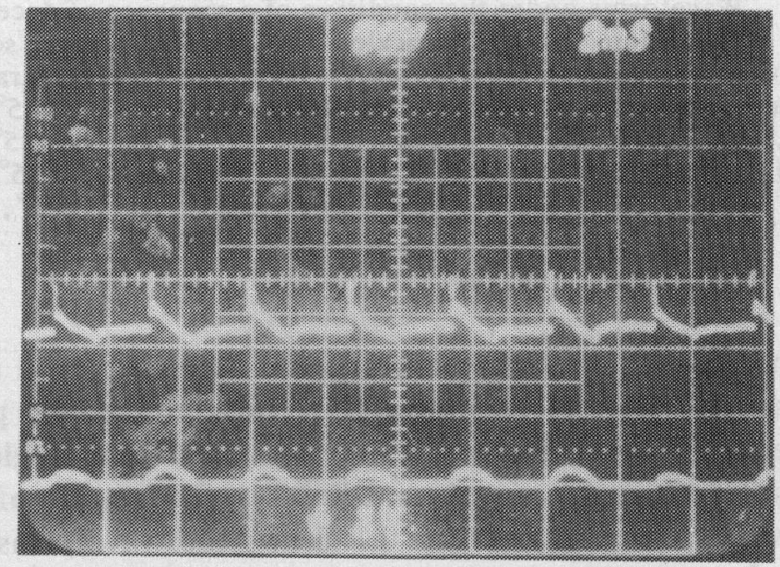

(f)

Fig. 11. Waveforms of armature voltage and current, horizontal scale: $2 \mathrm{~ms} /$ div; voltage scale: $50 \mathrm{~V} / \mathrm{div}$ (upper trace); current scale: $\mathrm{amp} / \mathrm{div}$ (lower trace). (a) Firing angle $=\mathrm{A} 5^{\circ}$. (b) Firing angle $=$ $\mathrm{A} 35^{\circ}$. (c) Firing angle $=\mathrm{A} 65^{\circ}$. (d) Firing angle $=\mathrm{A} 95^{\circ}$. (e) Firing angle $=\mathrm{A} 125^{\circ}$. (f) Firing angle $=\mathrm{A} 155^{\circ}$.

the other group are not allowed to be fired to avoid shortcircuit damage.

\section{Protection}

The protection of overall system can be checked by hardware as well as by the microcomputer. The protection features in the microcomputer include: the failure of any phase of ac source by $\phi A, \phi B$, and $\phi C$ inputs, the crossover condition and current failure by $J P$ and $J N$ inputs. The multilevel protection increases the reliability of the overall system.

\section{RESULTS OF EXPERIMENT}

A $0.5-\mathrm{kW}$ permanent magnet dc motor $(90 \mathrm{~V}, 15 \mathrm{~A}, 3000$ $\mathrm{rmp}$ ) is driven by the antiparallel-connected three-phase thyristor dual converter described above. The complete experimental setup is shown in Fig. 10. The waveforms of arma- 


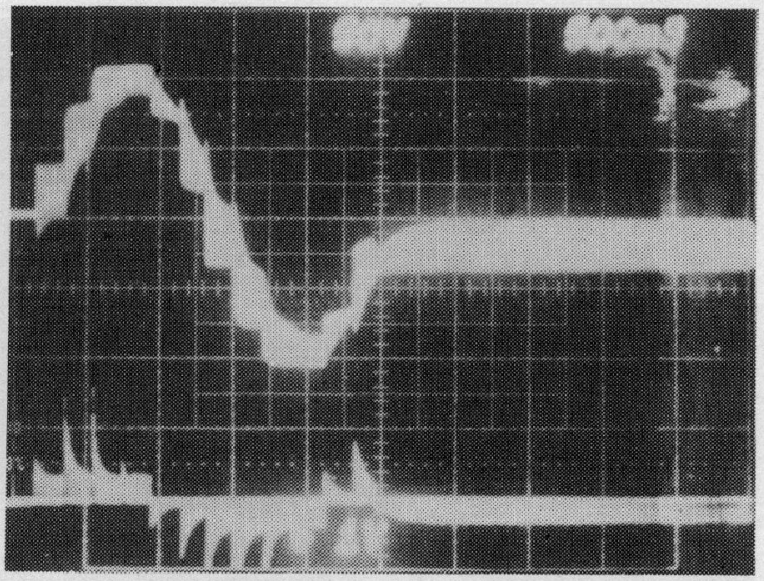

(a)

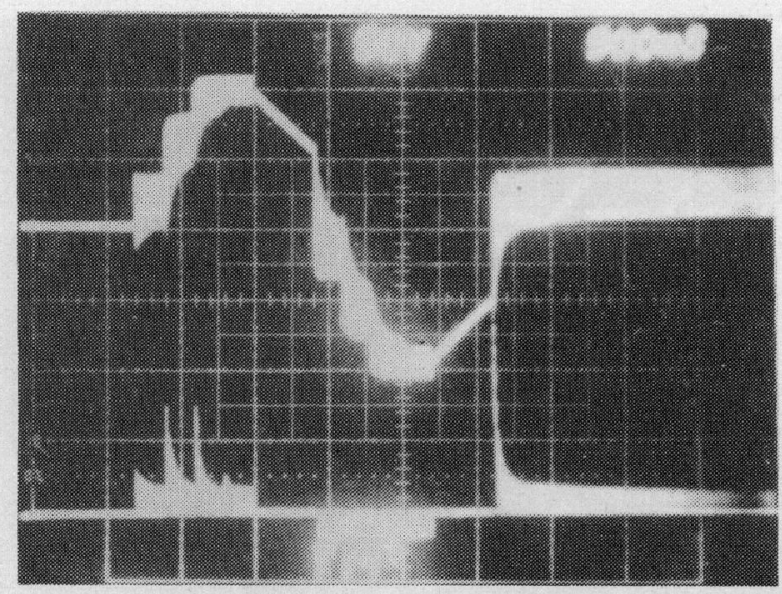

(b)

Fig. 12. Waveforms under the condition of a sequence of deceleration and acceleration, horizontal scale: $500 \mathrm{~ms} / \mathrm{div}$; voltage scale: 50 V/div (upper trace); current scale: $10 \mathrm{amp} /$ div (lower trace). (a) Fìring angle sequence (200 ms per firing angle): $\mathrm{A} 95^{\circ}, \mathrm{A} 65^{\circ}, \mathrm{A} 35^{\circ}$, $\mathrm{A} 5^{\circ}, \mathrm{B} 155^{\circ}, \mathrm{B} 125^{\circ}, \mathrm{B} 95^{\circ}, \mathrm{B} 65^{\circ}, \mathrm{B} 35^{\circ}, \mathrm{B} 5^{\circ}, \mathrm{A} 155^{\circ}, \mathrm{A} 125^{\circ}, \mathrm{B} 95^{\circ}$ (b) Firing angle sequence (200 ms per firing angle): $\mathrm{A} 95^{\circ}, \mathrm{A} 65^{\circ}$, $\mathrm{A} 35^{\circ}, \mathrm{A} 5^{\circ}, \mathrm{A} 95^{\circ}, \mathrm{A} 120^{\circ}, \mathrm{B} 95^{\circ}, \mathrm{B} 65^{\circ}, \mathrm{B} 35^{\circ}, \mathrm{B} 5^{\circ}, \mathrm{B} 95^{\circ}, \mathrm{B} 120^{\circ}$, A $95^{\circ}$.

ture voltage and armature current are recorded by a storage oscilloscope. The microcomputer is programmed to provide a sequence of firing angles. Define $A n^{\circ}$ as a firing angle of $n^{\circ}$ for positive current control, and $B n^{\circ}$ as a firing angle of $n^{\circ}$ for negative current control. Fig. 11 shows the waveforms under various firing conditions. These include the continuous current mode (Fig. 11(a)) and discontinuous current mode, the normal region and regeneration-braking region (Fig. 11(e) and (f)). The results of experiments are stable for the full range of firing angle between $0^{\circ}$ and $180^{\circ}$. Two examples of dynamic responses are shown in Figs. 12 and 13. In Fig. 12, the firing angle is set as a sequence of accelerations and decelerations in both directions. Fig. 12(a) shows the response with regeneration braking capability. Fig. 12(b) shows the response without regeneration braking. The decelerating capacity is very good for the case that the regeneration braking is used as compared to the case without regeneration braking. Fig. 13 shows the transient response of acceleration and deceleration. The de-

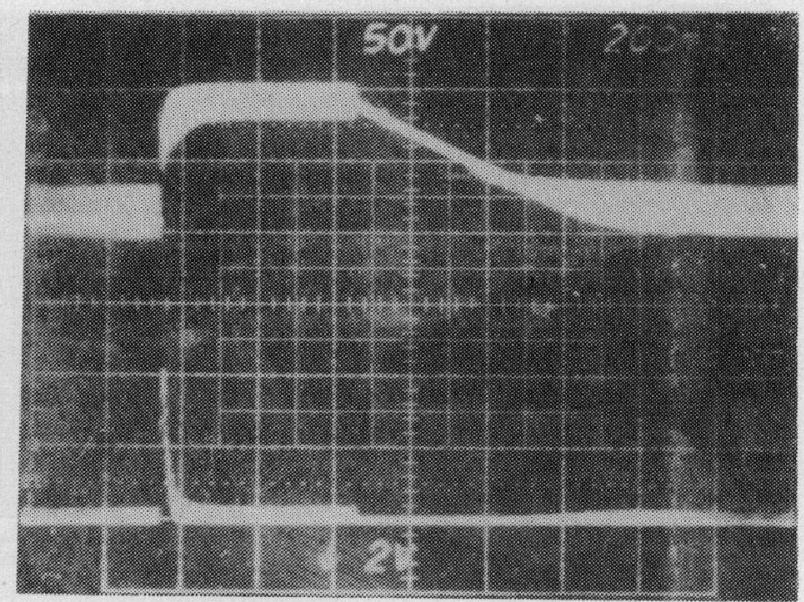

(a)

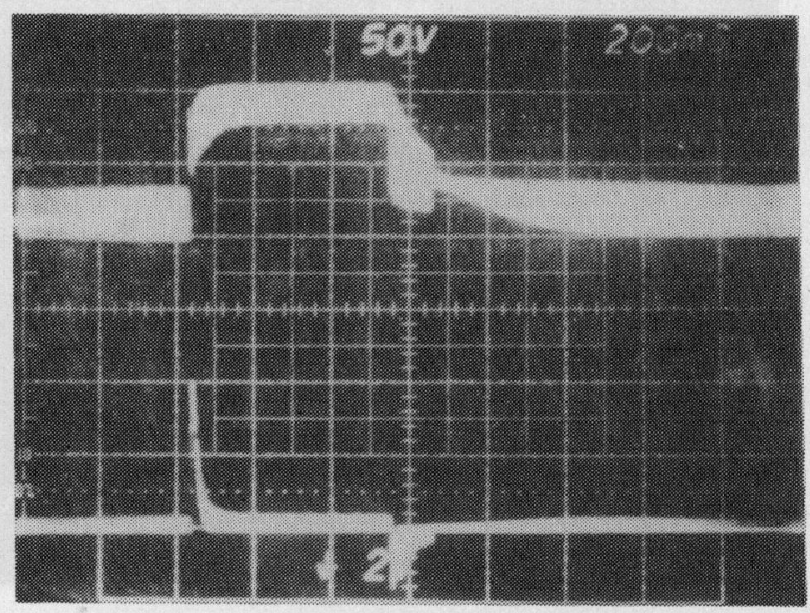

(b)

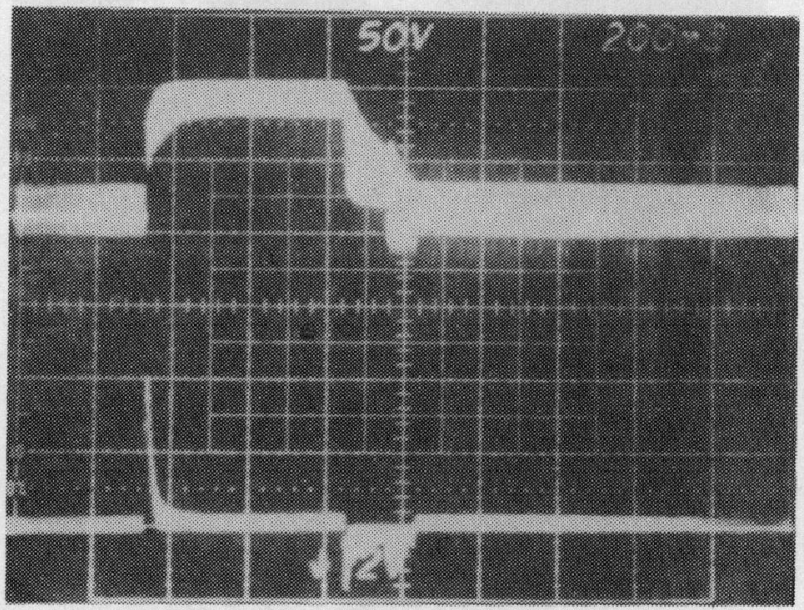

(c)

Fig. 13. Waveforms under transient conditions, horizontal scale: 200 $\mathrm{ms} /$ div; voltage scale: $50 \mathrm{~V} / \mathrm{div}$ (upper trace), current scale: $20 \mathrm{amp} /$ div (lower trace). (a) Firing angle sequence: $A 95^{\circ}$ for $1 \mathrm{~s}, \mathrm{~A} 35^{\circ}$ for $500 \mathrm{~ms}$, then, $\mathrm{A} 95^{\circ}$. (b) Firing angle sequence: $\mathrm{A} 95^{\circ}$ for $1 \mathrm{~s}, \mathrm{~A} 35^{\circ}$ for $500 \mathrm{~ms}, B 145^{\circ}$ for $100 \mathrm{~ms}$, then $A 95^{\circ}$. (c) Firing angle sequence: $\mathrm{A} 95^{\circ}$ for $1 \mathrm{~s}, \mathrm{~A} 35^{\circ}$ for $500 \mathrm{~ms}, \mathrm{~B} 145^{\circ}$ for $100 \mathrm{~ms}, \mathrm{~B} 110^{\circ}$ for 100 $\mathrm{ms}$, then $\mathrm{A} 95^{\circ}$.

celerating capacity is still good for the case that the regeneration braking is used. Although the response of deceleration is worse than the response of acceleration, the difference be- 
tween them would be less if a velocity feedback is used for a closed loop control.

\section{CONCLUSION}

A fast-response antiparallel-connected three-phase thyristor dual converter is presented. Taking advantage of digital circuits and microprocessor with new algorithm, the distinct features of this scheme are as follows:

1) The range of firing angle is $0^{\circ}-180^{\circ}$ for both positive and negative current control and the maximum delay angle still maintains less than $60^{\circ}$.

2) With the firing angle in the range of $120^{\circ}-180^{\circ}$ used as the regeneration braking region, a good motor decelerating capability is achieved.

3) To check the condition of load current, the cross-over damage is protected with minimum crossover time.

4) This scheme is implemented by all digital circuits. With minimum components and without any adjustment, high system reliability is expected.

\section{REFERENCES}

[1] T. Krishnan and B. Ramaswami, "Speed control of dc motor using thyristor dual converter," IEEE Trans. Ind. Electron. Contr. Instrum., vol. IECI-23, pp. 391-399, Nov. 1976.

[2] —-, "A fast-response DC motor speed control system," IEEE Trans. Ind. Appl., vol. IA-10, pp. 643-651, Sept. 1974.

[3] D. L. Duff and A. Ludbrook, "Reversing thyristor armature dual converter with logic crossover control,"' IEEE Trans. Ind. Gen. Appl., vol. IGA-1, pp. 216-222, 1965.

[4] B. Ilango et al., "Firing circuit for three-phase thyristor-bridge rectifier," IEEE Trans. Ind. Electron. Contr. Instrum., vol. IECI25, pp. 45-49, Feb. 1978.

[5] T. Ohmae et al., "A microprocessor-controlled fast-response speed regulator with dual mode current loop for DCM drives,"' IEEE Trans. Ind. Appl., vol. IA-16, pp. 388-394, May 1980.

[6] A. K. Lin and W. W. Koepsel, "A microprocessor speed control system,"' IEEE Trans. Ind. Electron. Contr. Instrum., vol. IECI24, pp. 241-247, Aug. 1977.

\title{
A Real-Time Digital Signal Analyzer Correlator Averager Power Spectral Density Analyzer
}

\author{
S. GANESAN, GIRIJA GOPALRATHNAM, AND M. RENUKADEVI
}

\begin{abstract}
The digital signal analyzer described here computes the values of auto- and cross-correlation functions, recovers signals buried in noise, and computes cross- and auto-power spectral density at 100 equally spaced points on the time-delay axis or frequency axis. The results are presented on an oscilloscope or on an $X-Y$ recorder.

The digital technique used, the averaging modes available, the theory of extraction of signal from noise by cross correlation with unit impulses, coarse quantization for input signals, and the technique for obtaining power spectral density from correlation function are discussed. All computations are performed digitally, i.e., delaying samples, multiplication, averaging, generating sinusoidal functions, modifications for power spectral density output by the Hamming window, CRT, and $X-Y$ recorder interface with interpolation between adjacent points, etc.
\end{abstract}

Manuscript received May 18, 1979.

The authors are with the National Aeronautical Laboratory, Post Bad No. 1779, Bangalore, 560017, India.
A comparison of performance of auto-correlation, cross correlation, and signal averaging is presented. The use of a microprocessor for the above application is also briefly mentioned. The applications of the instrument are mentioned.

\section{INTRODUCTION}

$\mathbf{R}$ EAL-TIME analysis of random signals requires measurements which are most conveniently and accurately made in the time domain. Subsequent information processing and design work may employ frequency domain techniques. This paper describes a real-time signal analyzer for correlation and spectrum analysis. The power spectrum is obtained here by Fourier cosine transformation of the correlation function.

The correlator computes simultaneously the values of autoor cross-correlation function of the analog input signals at 100 equally spaced points on the time-delay axis. The com- 